\title{
Underutilization of Statins for Prevention of Cardiovascular Disease among Primarily African-American HIV-Infected Patients
}

Shashwatee Bagchi ${ }^{1,2},{ }^{*}$, Pankti Patel ${ }^{1}$, Rawan Faramand ${ }^{3}$, Shana Burrowes ${ }^{4}$, Mian B. Hossain ${ }^{5}$, Shyamasundaran Kottilili1,2, Michael Miller ${ }^{6,7}$, Lori E. Fantry ${ }^{1,2}$ and Robert R. Redfield ${ }^{1,2}$

Institute of Human Virology, University of Maryland School of Medicine, Baltimore, MD, USA

${ }^{2}$ Division of Infectious Diseases, University of Maryland School of Medicine, Baltimore, MD, USA

${ }^{3}$ Department of Medicine, University of Maryland School of Medicine, Baltimore, MD, USA

${ }^{4}$ Department of Epidemiology and Human Genetics, University of Maryland School of Medicine, Baltimore, MD, USA

${ }^{5}$ School of Community Health and Policy, Department of Statistics, Morgan State University, Baltimore, MD, USA

${ }^{6}$ Department of Epidemiology \& Public Health, University of Maryland School of Medicine, Baltimore, MD, USA

${ }^{7}$ Division of Cardiovascular Medicine, University of Maryland School of Medicine, Baltimore, MD, USA

\begin{abstract}
Background: Studies have consistently demonstrated that statin therapy reduces CHD-related mortality, but HIVinfected individuals are frequently undertreated for hyperlipidemia. Therefore, we sought to: 1 . determine whether the numbers of patients recommended for statin therapy differed using the 2004 and 2013 guidelines; 2 . evaluate the proportion of recommended patients who were actually receiving statins; and 3 . evaluate the factors associated with statin prescription.
\end{abstract}

Methods: Conducted cross-sectional analysis of a retrospective cohort. 100 patients receiving care at an academic inner-city HIV clinic in 2008 were reviewed. The atherosclerotic vascular disease (ASCVD) risk score was calculated using the 2013 Pooled Cohort Equation and the 2004 and 2013 guidelines were applied to evaluate numbers of patients recommended for statin therapy. Proportions were used to report patients receiving statins among those who were recommended for treatment and several unadjusted logistic regression analyses were performed to identify factors associated with utilization of statins in recommended patients.

Results: 81 participants were included in the final analysis. Substantially larger numbers of HIV-infected individuals were recommended to receive statin therapy for CHD risk reduction when applying the 2013 guidelines compared to the 2004 guidelines, but less than half received statins for primary prevention as recommended. Prescription of statins was not associated with either ASCVD risk score or many traditional CHD risk factors. Diabetes mellitus was associated with increased odds of receiving statin therapy whereas hepatitis $\mathrm{C}$ co-infection and current smoking status were associated with decreased odds of receiving statins.

Conclusions: There is an increased, large and unmet need to increase statin use for prevention of CHD. Underutilization of statins was most pronounced among HIV-hepatitis C co-infected patients and HIV-infected smokers.

Keywords: HIV/AIDS; Atherosclerotic vascular disease and HIV; Coronary heart disease and HIV; Statins and HIV; ASCVD risk score; CHD; Statins; Coronary heart disease and Hepatitis C; Statins and Hepatitis C

\section{Introduction}

Coronary heart disease (CHD) represents a major cause of death in HIV-infected patients [1-6]. Many factors contribute to premature CHD risk in HIV-infected individuals including traditional CHD risk factors (dyslipidemia, hypertension, diabetes), lifestyle factors (cigarette smoking and illicit substance use), and HIV-related (inflammation, hypercoagulability, immune activation, effects of antiretroviral therapy (ART) [6-12].

HIV-infected patients often have abnormal lipid metabolism, particularly hypertriglyceridemia and decreased high-density lipoprotein cholesterol (HDL-c) levels due to HIV infection itself and the use of ART, particularly protease inhibitors [13-19]. For this reason, the Infectious Disease Society of America recommends screening for dyslipidemia prior to initiating ART and three to six months after starting therapy and at least annually thereafter [20].

The 2004 National Education Program Adult Treatment Plan III (NCEP ATPIII) guidelines helped HIV clinicians determine lifestyle and pharmacological interventions based on patients' lipid profiles and their 10-year risk of developing CHD using the 2002 Framingham risk calculation [21,22]. The main pharmacological intervention recommended to treat dyslipidemia is statins. In 2013, the ACC/AHA developed another risk score calculator that provided the composite atherosclerotic vascular disease (ASCVD) risk score using the Pooled Cohort Equation to assess patients' 10-year risk of developing CHD. They advocated using these scores to identify patients with elevated CHD risk who may benefit from moderate- or high-intensity statin therapy while de-emphasizing LDL-c cutpoints to guide statin therapy [23].

Studies have consistently demonstrated that statin therapy reduces

*Corresponding author: Shashwatee Bagchi, Institute of Human Virology and Division of Infectious Diseases, University of Maryland School of Medicine, 725 West Lombard Street, N359, Baltimore, MD 21201, USA, Tel: 410-706-4606; E-mail: sbagchi@som.umaryland.edu

Received July 14, 2014; Accepted September 04, 2015; Published September 12, 2015

Citation: Bagchi S, Patel P, Faramand R, Burrowes S, Hossain MB, et al. (2015) Underutilization of Statins for Prevention of Cardiovascular Disease among Primarily African-American HIV-Infected Patients. J AIDS Clin Res 6: 499. doi:10.4172/2155-6113.1000499

Copyright: (C) 2015 Bagchi S, et al. This is an open-access article distributed under the terms of the Creative Commons Attribution License, which permits unrestricted use, distribution, and reproduction in any medium, provided the original author and source are credited. 
CHD-related mortality, but HIV-infected individuals are frequently undertreated for hyperlipidemia and associated CHD risk factors [24-27]. However, some recent reports of decreasing CHD-associated mortality in select HIV populations have postulated that more aggressive control of CHD risk factors such as high blood pressure and abnormal lipid levels may account for the declines in some populations $[28,29]$.

We hypothesized that more patients would be recommended for statin treatment using the $2013 \mathrm{ACC} / \mathrm{AHA}$ guidelines than with the 2004 NCEP ATP III guidelines even though this would still represent less than $50 \%$ of eligible patients using the updated guidelines. Therefore, the primary purpose of our study was to determine whether the numbers of patients recommended for statin therapy differed using the two guidelines and, secondarily, to evaluate the proportion of recommended patients who were actually receiving statins and the factors associated with statin use.

\section{Methods}

\section{Study population}

We reviewed the medical records of $100 \mathrm{HIV}$-infected patients treated at the Evelyn Jordan Center (EJC), a large inner city HIV clinic associated with the University of Maryland Medical Center (UMMC). To be eligible for the study, participants had to be at least 18 years old, enrolled in and receiving HIV care at EJC on June 1,2008, and have at least two routine HIV visits between June 1, 2008 and May 31, 2012. We selected the first 100 charts based on medical record numbers generated in chronological order to determine the feasibility of abstracting and collecting data from these medical charts for a larger retrospective cohort study. One patient had more than one medical record number resulting in 99 eligible patients remaining. Of the 99 eligible participants, 81 had data for every variable required to calculate the ASCVD risk score using the Pooled Cohort Equation [23, 30]. The calculated ASCVD risk score is analogous to the Framingham risk score in that it describes an individual's 10 year risk of developing CHD.

\section{Data collection}

Data were collected for routine HIV visits at 3 month intervals (maximum of 4 visits per 12 month period) from June 1, 2008 to May 31, 2012 as part of the larger retrospective cohort study. A visit was defined as routine if it was a follow-up for HIV, included physical exams and addressed health maintenance issues. The presence of medical diagnoses and receipt of medications was based on documentation in the medical chart following review of the clinic and hospital medical record. The diagnosis of clinical depression was based on mental health provider notes or treatment of depression with appropriate psychiatric medication, rather than patient self-report to minimize the possibility of misdiagnosis. CHD event was defined as one of the following: history of an acute coronary syndrome (e.g. unstable angina), myocardial infarction (MI), clinical or arteriographically proven coronary artery disease (CAD) and ischemic cardiomyopathy. Cerebrovascular disease was defined as stroke or transient ischemic attack. ASCVD was defined as either CHD or cerebrovascular disease. Laboratory values and ranges were based on assays used by the UMMC reference laboratory, Labcorp. Data collected from the first 100 charts as described above were analyzed for this study.

\section{Statistical methods}

We performed a cross-sectional analysis of 81 participants in EJC during 2008. ASCVD risk scores were calculated using the 2013 Pooled
Cohort Equation endorsed by the ACC/AHA [23]. Recommendation for statin therapy using the 2004 NCEP ATP III guidelines was based on LDL-c levels, ASCVD risk score, and other risk factors including current cigarette smoking, hypertension or on antihypertensive medication, low HDL-c $(<40 \mathrm{mg} / \mathrm{dL})$, family history of ASCVD in first degree relatives, and age (men $\geq 45$ years; women $\geq 55$ years) [21,22]. Patients recommended for statin therapy using the 2013 ACC/AHA guidelines were those with prior ASCVD and those without known ASCVD and one of the following: 1) ASCVD risk score $\geq 7.5 \%, 2$ ) diabetes mellitus 40-75 years and LDL-c $\geq 70 \mathrm{mg} / \mathrm{dl}$, or 3) LDL-c $\geq 190$ $\mathrm{mg} / \mathrm{dl}[23,30]$. The proportion of patients receiving statins among those who were recommended for treatment are reported. For the secondary objective, receipt of statins was considered as a dichotomous outcome variable and several unadjusted (bivariate) logistic regression analyses were performed to identify factors associated with utilization of statins in patients recommended for statin therapy.

The analyses were performed using Stata 12.1 (StataCorp, 2011). A $p$-value $<0.05$ using a two tailed $\mathrm{z}$-test for the odds ratio was considered significant.

\section{Results}

The 81 participants were predominately men (61.7\%) and African-American (95.1\%) with a median age of 52 years (Table 1 and Supplemental Table 1). The most common HIV risk factor was injection drug use (IDU) (60.5\%). The median CD4 cell count was 343 cells $/ \mathrm{mm}^{3}$. The majority were receiving ART (87\%) with mostly protease inhibitors and nucleoside reverse transcriptase inhibitors, and $55.5 \%$ were virologically suppressed. Over $70 \%$ were co-infected with hepatitis B and/or C. Almost half (45.7\%) had a body mass index $>25 \mathrm{~kg} / \mathrm{mm}^{2}$ and $24.7 \%$ had diabetes mellitus. One of 81 participants received lipid-lowering pharmacological intervention other than statins. Characteristics of the 18 excluded patients were not significantly different from those of included patients, and none of the excluded participants received a non-statin lipid-lowering medication (data not shown).

The median ASCVD risk scores of men and women without prior ASCVD in 2008 were $10.8(\mathrm{~N}=45)$ and $4.0(\mathrm{~N}=23)$, respectively. In 2012, median ASCVD risk scores of men and women were $10.7(\mathrm{~N}=33)$ and $4.0(\mathrm{~N}=15)$, respectively (Table $2 \mathrm{~A})$. In 2008, among individuals without prior ASCVD, two patients (2.9\%) were recommended for statin therapy using the 2004 NCEP ATP III guidelines compared to 41 patients $(60.3 \%)$ using the 2013 ACC/AHA guidelines. Of these recommended individuals, 12 received statins. In 2008, among individuals with prior ASCVD, eight patients (61.5\%) were recommended for statin therapy using the 2004 guidelines compared to 13 patients (100\%) using the 2013 guidelines. Of these recommended individuals, six received statins.

In 2012, among individuals without prior ASCVD, one patient (2.1\%) was recommended for statin therapy using the 2004 guidelines compared to 27 patients (56.3\%) using the 2013 guidelines. Of these recommended individuals, nine received statins. In 2012, among individuals with prior ASCVD, none were recommended for statin therapy using the 2004 guidelines compared to three patients $(60 \%)$ using the 2013 guidelines. Of these three individuals, two received statins (Table 2A).

There were substantial differences in the proportion of patients recommended for statin therapy who were actually receiving statins when comparing the 2004 NCEP ATP III and the 2013 ACC/AHA guidelines (Table 2B). For primary prevention in 2008, statins were 


\begin{tabular}{|c|c|c|c|}
\hline \multirow[t]{2}{*}{ Variable } & $\begin{array}{c}\text { Men } \\
(n=50)\end{array}$ & $\begin{array}{c}\text { Women } \\
(n=31)\end{array}$ & $\begin{array}{c}\text { Total } \\
(n=81)\end{array}$ \\
\hline & $\%(n)$ & $\%(n)$ & $\%(n)$ \\
\hline \multicolumn{4}{|l|}{ Socio-demographic Indicators } \\
\hline Sex & $61.7(50)$ & $38.3(31)$ & $100(81)$ \\
\hline Age in years (median) & 54 & 50 & 52 \\
\hline \multicolumn{4}{|l|}{ Race } \\
\hline Black/African American & $94.0(47)$ & $96.8(30)$ & $95.1(77)$ \\
\hline \multicolumn{4}{|l|}{ Behavioral indicators } \\
\hline Cigarette Smoker & $56.0(28)$ & $54.8(17)$ & $55.6(45)$ \\
\hline Alcohol Use & $26.0(13)$ & $22.6(7)$ & $24.7(20)$ \\
\hline Illicit drug use & $6.0(3)$ & $22.6(7)$ & $12.4(10)$ \\
\hline \multicolumn{4}{|l|}{ Mode of transmission } \\
\hline IDU & $68.0(34)$ & $48.4(15)$ & $60.5(49)$ \\
\hline Heterosexual & $20.0(10)$ & $51.6(16)$ & $32.1(26)$ \\
\hline MSM & $12.0(6)$ & - & $7.4(6)$ \\
\hline \multicolumn{4}{|l|}{ Clinical Indicators } \\
\hline \multicolumn{4}{|l|}{ ARVs } \\
\hline Pls & $53.7(22)$ & $44.0(11)$ & $50.0(33)$ \\
\hline NNRTIs & $36.6(15)$ & $52.0(13)$ & $42.4(28)$ \\
\hline NRTIs only & $17.1(7)$ & $8.0(2)$ & $13.6(9)$ \\
\hline Median CD4 cell count (cells/mm³) & 392 & 123 & 343 \\
\hline Undetectable viral load (copies/ml) & $60.0(30)$ & $48.4(15)$ & $55.6(45)$ \\
\hline GFR $>=59$ & $84.0(42)$ & $80.7(25)$ & $82.7(67)$ \\
\hline Diabetes mellitus & $22(11)$ & $29.0(9)$ & $24.7(20)$ \\
\hline Hepatitis C & $82.0(41)$ & $58.1(18)$ & $72.8(59)$ \\
\hline Prior CHD event & $6.0(3)$ & $6.5(2)$ & $6.2(5)$ \\
\hline Prior Cerebrovascular Disease & $4.0(2)$ & $19.4(6)$ & $9.9(8)$ \\
\hline Prior non-ASCVD CVD event & $12.0(6)$ & $3.2(1)$ & $8.6(7)$ \\
\hline Family history of CVD & $66.0(33)$ & $77.4(24)$ & $70.4(57)$ \\
\hline Antihypertensive Use & $48.0(24)$ & $45.2(14)$ & $46.9(38)$ \\
\hline Systolic blood pressure (median) & 132 & 129 & 130 \\
\hline Total cholesterol (median) & 161 & 156 & 157 \\
\hline HDL (median) & 41 & 44 & 41 \\
\hline LDL (median) & 84 & 91 & 87 \\
\hline Triglycerides (median) & 138 & 116 & 120 \\
\hline
\end{tabular}

Notes: $\mathrm{MSM}=$ men who have sex with men, IDU= injection drug use, $\mathrm{PI}=$ protease inhibitor, NNRTI= non-nucleoside reverse transcriptase inhibitor, NRTI= nucleoside reverse transcriptase inhibitor, $\mathrm{CHD}=$ coronary heart disease, $\mathrm{ASCVD}=$ atherosclerotic vascular disease, CVD= cardiovascular disease, GFR=Glomerula filtration rate, $\mathrm{HDL}=$ high-density lipoprotein, $\mathrm{LDL}=$ low-density lipoprotein Table 1: Characteristics of HIV- Infected Participants at the Evelyn Jordan Center of the University of Maryland Medical Center

Table 1: Characteristics of HIV- Infected Participants at the Evelyn Jordan Center of the University of Maryland Medical Center

overprescribed in 10 out of 12 patients using the 2004 guidelines and under prescribed using the 2013 guidelines as only 12 of 41 patients received treatment. Similarly, for primary prevention in 2012 only one patient was recommended but nine received statins using the 2004 guidelines compared to nine of 27 recommended patients received treatment using the 2013 guidelines. For secondary prevention in 2008, six of eight recommended patients received statins using the 2004 guidelines compared to six of 13 recommended patients using the 2013 guidelines. For secondary prevention in 2012, two of three recommended patients received statins using the 2013 guidelines. There were no patients recommended for statins using the 2004 guidelines.

Diabetes mellitus $(\mathrm{OR}=4.73,95 \% \mathrm{CI}=1.53,14.63 ; p=0.007)$ was the only factor significantly associated with increased odds of statin use whereas current smoking status $(\mathrm{OR}=0.21,95 \% \mathrm{CI}=0.07,0.67 ; p=0.008)$ and hepatitis $\mathrm{C}(\mathrm{OR}=0.13,95 \% \mathrm{CI}=0.04,0.42 ; p<0.001)$ were significantly associated with decreased odds of statin use (Table 3 ). Gender, race, the ASCVD risk score, other traditional CHD risk factors, and the HIVrelated parameters were not associated with statin use.

\begin{tabular}{|c|c|c|c|c|c|c|c|c|}
\hline & \multicolumn{2}{|c|}{$\begin{array}{c}\text { Median (n) } \\
\text { ACC/AHA } 2013 \\
\text { ASCVD Risk } \\
\text { Score }^{\mathrm{a}}\end{array}$} & \multicolumn{2}{|c|}{$\begin{array}{l}\text { Recommended } \\
\text { for Statin } \\
\text { Therapy NCEP } \\
\text { ATP III } 2004 \\
\text { Guidelines }^{\mathrm{b}}\end{array}$} & \multicolumn{2}{|c|}{$\begin{array}{l}\text { Recommended } \\
\text { for Statin } \\
\text { Therapy ACC/ } \\
\text { AHA 2013 } \\
\text { Guidelines }^{\circ}\end{array}$} & \multicolumn{2}{|c|}{$\begin{array}{l}\text { Receiving } \\
\text { Statin } \\
\text { Therapy }\end{array}$} \\
\hline & Male & Female & Male & Female & Male & Female & Male & Female \\
\hline $\begin{array}{l}\text { No prior } \\
\text { ASCVD in } \\
2008\end{array}$ & $10.8(45)$ & $4.0(23)$ & 1 & 1 & 34 & 7 & 8 & 4 \\
\hline $\begin{array}{l}\text { Known } \\
\text { ASCVD in } \\
2008\end{array}$ & $\begin{array}{c}27.3 \\
(5)\end{array}$ & $\begin{array}{c}12.7 \\
(8)\end{array}$ & 4 & 4 & 5 & 8 & 2 & 4 \\
\hline $\begin{array}{l}\text { Patients in } \\
2012 \text { who } \\
\text { had no prior } \\
\text { ASCVD and } \\
\text { at least one } \\
\text { visit in } 2012\end{array}$ & $10.7(33)$ & $\begin{array}{l}4.0 \\
(15)\end{array}$ & 1 & 0 & 24 & 3 & 6 & 3 \\
\hline $\begin{array}{l}\text { Known } \\
\text { ASCVD in } \\
2012\end{array}$ & $\begin{array}{c}17.7 \\
(3)\end{array}$ & $\begin{array}{l}6.7 \\
(2)\end{array}$ & 0 & 0 & 1 & 2 & 1 & 1 \\
\hline
\end{tabular}

ASCVD = atherosclerotic vascular disease; $A C C / A H A=$ American College of Cardiology/American Heart Association; NCEP= National Cholesterol Education Program; ATP= Adult Treatment Panel; a: http://tools.cardiosource.org/ASCVDRisk-Estimator/; b: National Cholesterol Education Program (NCEP) Expert Panel on Detection, Evaluation, and Treatment of High Blood Cholesterol in Adults (Adult Treatment Panel III). Third report of the National Cholesterol Education Program (NCEP) expert panel on detection, evaluation, and treatment of high blood cholesterol in adults (Adult Treatment Panel III) final report. Circulation 2002 106(25):3143-3421; c: Stone NJ, Robinson J, Lichtenstein AH, et al. 2013 ACC/ AHA Guideline on the Treatment of Blood Cholesterol to Reduce Atherosclerotic Cardiovascular Risk in Adults: A Report of the American College of Cardiology/ American Heart Association Task Force on Practice Guidelines. J Am Coll Cardiol 2013.

Table 2A: Median Framingham Risk Score, Recommended and Statin Use in HIV-Infected Participants at the Evelyn Jordan Center of the University of Maryland Medical Center.

\begin{tabular}{|c|c|c|c|}
\hline & \multirow{2}{*}{$\begin{array}{c}\text { Receiving } \\
\text { Statin } \\
\text { Therapy }\end{array}$} & $\begin{array}{c}|c| \\
\text { Percentage of Recommended Patients } \\
\text { Receiving Statins (n recommended) }\end{array}$ \\
\cline { 3 - 4 } & NCEP ATP III Guidelines & $\begin{array}{c}\text { 2004 } \\
\text { 2013 ACC/AHA } \\
\text { Guidelines }^{\mathrm{b}}\end{array}$ \\
\hline $\begin{array}{c}\text { Primary } \\
\text { Prevention 2008 }\end{array}$ & 12 & $600 \%(2)$ & $29 \%(41)$ \\
\hline $\begin{array}{c}\text { Secondary } \\
\text { Prevention 2008 }\end{array}$ & 6 & $75 \%(8)$ & $46 \%(13)$ \\
\hline Primary Prevention & 9 & $900 \%(1)$ & $33 \%(27)$ \\
\hline $\begin{array}{c}\text { 2012 } \\
\text { Secondary } \\
\text { Prevention 2012 }\end{array}$ & 2 & NA (0) & $67 \%(3)$ \\
\hline
\end{tabular}

$\mathrm{NCEP}=$ National Cholesterol Education Program; ATP $=$ Adult Treatment Panel; ACC/AHA = American College of Cardiology/American Heart Association; NA= not applicable; a: National Cholesterol Education Program (NCEP) Expert Panel on Detection, Evaluation, and Treatment of High Blood Cholesterol in Adults (Adult Treatment Panel III). Third report of the National Cholesterol Education Program (NCEP) expert panel on detection, evaluation, and treatment of high blood cholesterol in adults (Adult Treatment Panel III) final report. b. 2013 ACC AHA Guideline on the Treatment of Blood Cholesterol to Reduce Atherosclerotic Cardiovascular Risk in Adults: A Report of the American College of Cardiology/ American Heart Association Task Force on Practice Guidelines.

Table 2B: Statin Recommended and Actual Usage in HIV-Infected Participants at the Evelyn Jordan Center of the University of Maryland Medical Center 


\begin{tabular}{|c|c|c|c|}
\hline & \multicolumn{2}{|c|}{ Receipt of Statin Therapy } & \multirow{2}{*}{$p$-value } \\
\hline & $\mathbf{N}$ & Odds Ratio $(95 \% \mathrm{Cl})$ & \\
\hline \multicolumn{4}{|c|}{ Socio-demographic Indicators } \\
\hline Age in years & 81 & $1.07(0.98,1.17)$ & 0.137 \\
\hline Males & 50 & $0.72(0.25,2.08)$ & 0.542 \\
\hline \multicolumn{4}{|l|}{ Race } \\
\hline Caucasian & $4^{a}$ & - & - \\
\hline African-American & 77 & - & - \\
\hline \multicolumn{4}{|l|}{ Employment } \\
\hline Yes & 17 & $0.67(0.17,2.69)$ & 0.576 \\
\hline No (RC) & 58 & 1.00 & - \\
\hline \multicolumn{4}{|l|}{ Behavioral indicators } \\
\hline Current smoking & 45 & $0.21(0.07,0.67)$ & 0.008 \\
\hline Current Alcohol Use & 20 & $1.13(0.34,3.69)$ & 0.842 \\
\hline Current Illicit drug use & 10 & $0.84(0.16,4.38)$ & 0.840 \\
\hline \multicolumn{4}{|l|}{ Clinical Indicators } \\
\hline \multicolumn{4}{|l|}{ Time since HIV diagnosis } \\
\hline $5-10$ years $(R C)$ & 11 & 1.00 & - \\
\hline $11-20$ years & 32 & $1.26(0.22,7.22)$ & 0.795 \\
\hline$>20$ years & 38 & $1.40(0.25,7.68)$ & 0.701 \\
\hline Receiving ART & 62 & $2.96(0.61,14.23)$ & 0.176 \\
\hline Receiving Pls & 33 & $0.51(0.16,1.62)$ & 0.255 \\
\hline \multicolumn{4}{|c|}{$\begin{array}{l}\text { Most recent CD4 cell count (cells/ } \\
\qquad \mathrm{mm}^{3} \text { ) }\end{array}$} \\
\hline$<200(R C)$ & 11 & 1.00 & - \\
\hline$\geq 200$ & 68 & $3.08(0.37,25.91)$ & 0.301 \\
\hline \multicolumn{4}{|c|}{ Undetectable viral load (copies/ml) } \\
\hline Yes & 45 & $1.56(0.51,4.75)$ & 0.430 \\
\hline No (RC) & 35 & 1.00 & - \\
\hline \multicolumn{4}{|l|}{$\mathrm{BMI}(\mathrm{kg} / \mathrm{m} 2)$} \\
\hline$<30.0(\mathrm{RC})$ & 65 & 1.00 & - \\
\hline$\geq 30.0$ & 14 & $2.22(0.64,7.76)$ & 0.211 \\
\hline \multicolumn{4}{|l|}{ GFR $\left(\mathrm{ml} / \mathrm{min} / 1.73 \mathrm{~m}^{2}\right)$} \\
\hline$>=59(\mathrm{RC})$ & 67 & 1.00 & - \\
\hline$<59$ & 14 & $0.95(0.23,3.83)$ & 0.937 \\
\hline Diabetes Mellitus & 20 & $4.73(1.53,14.63)$ & 0.007 \\
\hline Hepatitis C co-infection & 59 & $(0.04,0.42)^{\mathbf{0 . 1 3}}$ & $<0.001$ \\
\hline Cancer* & 14 & $0.53(0.11,2.63)$ & 0.438 \\
\hline Prior non-ASCVD CVD & 7 & $0.56(0.06,4.97)$ & 0.602 \\
\hline Family history of CVD & 57 & $0.77(0.23,2.26)$ & 0.667 \\
\hline \multicolumn{4}{|l|}{ Total Cholesterol (mg/dl) } \\
\hline$\leq 200(R C)$ & 63 & 1.00 & - \\
\hline$>200$ & 18 & $3.01(0.95,9.50)$ & 0.06 \\
\hline \multicolumn{4}{|l|}{$\mathrm{LDL}(\mathrm{mg} / \mathrm{dl})$} \\
\hline$<160(R C)$ & 76 & 1.00 & - \\
\hline 160 or more & 2 & $3.47(0.21,58.45)$ & 0.388 \\
\hline \multicolumn{4}{|l|}{ Triglycerides (mg/dl) } \\
\hline$<200$ (RC) & 63 & 1.00 & - \\
\hline 200 or more & 17 & $2.32(0.71,7.52)$ & 0.161 \\
\hline \multicolumn{4}{|l|}{ ASCVD Risk Score } \\
\hline Elevated Risk & 45 & $0.99(0.29,3.41)$ & 0.993 \\
\hline Low Risk (RC) & 28 & 1.00 & - \\
\hline
\end{tabular}

Notes: ART $=$ antiretroviral therapy consisting of at least 3 antiretroviral medications: $\mathrm{PI}=$ protease inhibitor, $\mathrm{BMI}=$ body mass index, $\mathrm{ASCVD}=$ atherosclerotic vascular disease, $C V D=$ cardiovascular disease, GFR=Glomerular filtration rate, LDL=lowdensity lipoprotein

* $=$ history of cancer or active cancer diagnosis

$\mathrm{RC}$ is reference category

a there are no cases of statin therapy receipt among Caucasian.

Table 3: Factors Associated with Statin Therapy among HIV-Infected Participants at the Evelyn Jordan Center of the University of Maryland Medical Center

\section{Discussion}

In this study, we found that substantially larger numbers of HIVinfected individuals were recommended to receive statin therapy for CHD risk reduction when applying the 2013 ACC/AHA guidelines for treatment of cholesterol compared to the 2004 NCEP ATP III guidelines. We also found that prescription of statins was not associated with either ASCVD risk score or many traditional CHD risk factors, and that diabetes mellitus was associated with increased odds of receiving statin therapy whereas hepatitis $\mathrm{C}$ co-infection and current smoking status were associated with decreased odds of receiving statins. Finally, HIV-infected patients in this predominantly African American clinic with a large percentage of women and IDUs received statins for primary prevention less than half as often as recommended by current guidelines.

Pencina et al. demonstrated that greater numbers of patients in the general population would be recommended for statin therapy using the updated guidelines compared to the older guidelines, but a comparison of guidelines for statin initiation has been limited in the HIV population [31]. In our study, we found a marked difference in numbers of patients recommended for statin therapy for primary prevention: $2.9 \%$ using 2004 NCEP ATP III guidelines compared to $60.3 \%$ of our patients when using the 2013 ACC/AHA guidelines. This difference was much higher than that reported by Zanni et al. who reported that $8 \%$ of their $108 \mathrm{HIV}$-infected patients were recommended for statin therapy for primary prevention by the 2004 guidelines compared to $21 \%$ of patients when using the 2013 guidelines [32]. These differences in numbers of patients recommended for statins in the two studies may be partly due to differences in study population and design.

We also found that while more individuals than recommended were receiving statins for primary prevention using the 2004 NCEP ATP III guidelines only $29 \%$ and $33 \%$ recommended individuals were receiving them when the 2013 ACC/AHA guidelines were applied in 2008 and 2012, respectively. This comparison highlights the significantly larger numbers of HIV-infected patients who could benefit from more intensive CHD risk reduction measures using 2013 guidelines, which is significant given the excess, premature burden of CHD observed in HIV-infected individuals. It also suggests that provider perception may play a large role in statin prescription when considering the discrepancy between recommendation for statin therapy and actual use since patients were both over utilizing and underutilizing statins when applying different guidelines.

None of the reported studies to date have identified an association between hepatitis $\mathrm{C}$ co-infection and decreased statin use. The association of hepatitis $\mathrm{C}$ and statin use is important in light of our earlier study which demonstrated that chronic hepatitis $\mathrm{C}$ infection was associated with higher $\mathrm{CHD}$ risk [unpublished data]. A recent data analysis from the Multicenter AIDS Cohort Study (MACS) showed elevated transaminase levels were associated with not achieving LDL-c targets suggesting a reluctance of providers to initiate statins which are potentially hepatotoxic [33]. This may explain the underutilization of statins among HIV-hepatitis C co-infected patients.

Current smoking was also observed to be associated with decreased odds of statin use but this was not noted in the Data Collection on Adverse Events in Anti-HIV Drugs Study (D.A.D.) analysis from 19992006 of predominantly Caucasian men with comparatively much less IDU. The differences in findings may be due to differences in patient and provider study populations [34]. In the HIV Outpatient Study (HOPS) and MACS analyses, however, current smoking was associated 
with lesser achievement of target LDL-c goals which may be explained by lower LDL-c targets due to presence of this risk factor that require more aggressive lipid-lowering therapy [26,33]. These observations are important because of the higher prevalence and risk of MI attributed to smoking in the HIV population compared to the general population [8].

We found that diabetes mellitus was associated with increased odds of patients receiving statins. Similar associations were also observed in the D.A.D. cohort analysis [34]. However, the D.A.D analysis found that family history of CVD, elevated total cholesterol and hypertriglyceridemia were also associated with statin use, and this was not demonstrated in our study perhaps due to differences in study population, time periods investigated, or sample sizes and consequent power to detect these associations. Lichenstein et al. found that race and gender were associated with achievement of lipid targets in an analysis from the HOPS, but they did not identify factors associated with prescription of pharmacological treatment and the HOPS represented substantially more Caucasians, men, and much less IDU than our study population [26].

Finally, we found that the majority of HIV-infected individuals who met criteria for statin therapy using current guidelines were not receiving it. This finding was consistent with the suboptimal use of statins observed in the D.A.D. cohort and in the HIV-HEART study, but different than in the HOPS in which $81-87 \%$ of those with elevated LDL-c or non-HDL-c recommended for therapy were receiving treatment $[25,26,34]$. However, therapy in the HOPS data was defined much more broadly than in the current study and included prescription of one of numerous different lipid-lowering agents (statins, ezetimibe, bile acid sequestrants, nicotinic acid) and documentation of exercise.

The underutilization of statins was not only observed in primary prevention of CHD but also in secondary prevention of CHD in our study and in the D.A.D. cohort analysis. Though the D.A.D analysis showed that statin use had modestly increased over calendar time, peaking around 2001, our study did not reveal a similar increase of statin use over time. This lack of increase in statin use in our study may be due to the predominantly minority study population with majority IDU, relatively lower resources, poorer access, and less sustained engagement in care, which highlights the need of HIV providers caring for underserved populations to be more proactive and vigilant in prescribing statins for CHD risk reduction.

There are important strengths to our study. This is one of only two studies to our knowledge comparing the differences in numbers of HIV-infected patients recommended for statin therapy when applying the NCEP ATPIII 2004 versus the 2013 ACC/AHA guidelines. Second, our finding that HIV-hepatitis $\mathrm{C}$ coinfected individuals received even greater suboptimal statin use than HIV- monoinfected individuals is an important addition to the literature. Finally, our study population consists of demographic risk groups that are often underrepresented in larger HIV cohorts and is one of the few evaluating prescription of statins that included large percentage of women. This is important given the observed differential CHD rates in HIV-infected women compared to men in reports from Boston and France as well as in our earlier study $[2,4]$ [unpublished data].

There are important limitations to our study. First, the small sample size may have limited our ability to detect other significant associations with initiation of statins. We are reassured that other studies, including an abstract from the 2015 Conference on Retroviruses and Opportunistic Infections of the Veterans Affairs Clinical Case Registry of 13,293 HIV-infected males, evaluating the impact of the $2013 \mathrm{ACC} /$ AHA among HIV-infected patients have also reported increased numbers of HIV-infected recommended to be receiving statins [32]. Second, the cross-sectional nature of the study did not allow us to identify change of CHD risk factors associated with change of statin use over time nor allow us to report on statin initiation rather than statin utilization. However, both of these are appropriately being addressed in the longitudinal phase of our study. Third, the retrospective design did not allow capture of all data relevant to $\mathrm{CV}$ risk such as anthropometric measures and accurate assessment of lipodystrophy that may influence provider perception of CHD risk and prescription of statins. Lastly, we were not able to document individual provider use accurately and account for provider bias in our analysis.

In conclusion, our study demonstrated an increased, large and unmet need to increase statin use for prevention of CHD. Underutilization of statins based on the updated 2013 ACC/AHA guidelines was most pronounced among HIV-hepatitis $\mathrm{C}$ co-infected patients and HIV-infected smokers. Prescription of statins was not associated with objective, standardized CVD risk assessment tools but only with presence of a selected co-morbidity which suggests that HIV provider perception of individual patient need for statins likely plays a large role in practice behavior. Further studies evaluating utilization of statins are needed to inform and improve HIV provider knowledge of and adherence to current guidelines for prevention and management of CHD. HIV-specific guidelines regarding statin use are urgently needed.

\section{Acknowledgments}

Departmental funds were used for statistical support, and no grant funding was used for this study. The authors want to thank Gemechis Tollera and Alexandra Ward for their contributions to data collection for the article and Mona Baumgarten for reading and providing inputs on earlier drafts of the manuscript. All authors critically reviewed the manuscript and approve the final version of the manuscript.

\section{Reference}

1. Paisible AL, Chang CC, So-Armah KA, Butt AA, Leaf DA, et al. (2015) HIV infection, cardiovascular disease risk factor profile, and risk for acute myocardial infarction. J Acquir Immune Defic Syndr 68: 209-216.

2. Triant VA1, Lee H, Hadigan C, Grinspoon SK (2007) Increased acute myocardial infarction rates and cardiovascular risk factors among patients with human immunodeficiency virus disease. J Clin Endocrinol Metab 92: 2506-2512.

3. Currier JS1, Taylor A, Boyd F, Dezii CM, Kawabata H, et al. (2003) Coronary heart disease in HIV-infected individuals. J Acquir Immune Defic Syndr 33: 506-512.

4. Lang S1, Mary-Krause M, Cotte L, Gilquin J, Partisani M, et al. (2010) Increased risk of myocardial infarction in HIV-infected patients in France, relative to the general population. AIDS 24: 1228-1230.

5. Durand M, Sheehy O, Baril JG, Lelorier J, Tremblay CL (2011) Association between HIV infection, antiretroviral therapy, and risk of acute myocardial infarction: a cohort and nested case-control study using Quebec's public health insurance database. J Acquir Immune Defic Syndr. 57: 245-253.

6. Boccara F, Lang S, Meuleman C, Ederhy S, Mary-Krause M, et al. (2013) HIV and coronary heart disease: time for a better understanding. J Am Coll Cardiol 61: 511-523.

7. Triant VA (2012) HIV infection and coronary heart disease: an intersection of epidemics. J Infect Dis 205 Suppl 3: S355-361.

8. Rasmussen LD, Helleberg M, May MT, Afzal S, Kronborg G, et al. (2015) Myocardial infarction among Danish HIV-infected individuals: populationattributable fractions associated with smoking. Clin Infect Dis 60: 1415-1423.

9. Brown TT, Cole SR, Li X, Kingsley LA, Palella FJ, et al. (2005) Antiretroviral therapy and the prevalence and incidence of diabetes mellitus in the multicenter AIDS cohort study. Arch Intern Med 165: 1179-1184.

10. Nordell AD, McKenna M, Borges ÁH, Duprez D, Neuhaus J, et al. (2014 
Severity of cardiovascular disease outcomes among patients with HIV is related to markers of inflammation and coagulation. J Am Heart Assoc 3: e000844.

11. Lo J, Plutzky J (2012) The biology of atherosclerosis: general paradigms and distinct pathogenic mechanisms among HIV-infected patients. J Infect Dis 205 Suppl 3: S368-374.

12. Friis-Møller N, Sabin CA, Weber R, d'Arminio Monforte A, El-Sadr WM, et al. (2003) Combination antiretroviral therapy and the risk of myocardial infarction. N Engl J Med 349: 1993-2003.

13. El-Sadr WM, Mullin CM, Carr A, Gibert C, Rappoport C, et al. (2005) Effects of HIV disease on lipid, glucose and insulin levels: results from a large antiretroviral-naive cohort. HIV Med 6: 114-121.

14. Grunfeld C, Pang M, Doerrler W, Shigenaga JK, Jensen P, et al. (1992) Lipids, lipoproteins, triglyceride clearance, and cytokines in human immunodeficiency virus infection and the acquired immunodeficiency syndrome. J Clin Endocrinol Metab 74:1045-1052

15. Fellay J, Boubaker K, Ledergerber B, Bernasconi E, Furrer H, et al. (2001) Prevalence of adverse events associated with potent antiretroviral treatment: Swiss HIV Cohort Study. Lancet 358: 1322-1327.

16. Riddler SA, Li X, Otvos J, Post W, Palella F, et al. (2008) Antiretroviral therapy is associated with an atherogenic lipoprotein phenotype among HIV-1-infected men in the multicenter AIDS cohort study. J Acquired Immune Defic Syndr 48: 281-288

17. Rimland D, Guest JL, Hernández I, Del Rio C, Le NA, et al. (2005) Antiretroviral therapy in HIV-positive men is associated with increased apolipoprotein CIII in triglyceride-rich lipoproteins. HIV Med 6: 326-333.

18. Asztalos BF, Schaefer EJ, Horvath KV, Cox CE, Skinner S, et al. (2006) Protease inhibitor-based HAART, HDL, and CHD-risk in HIV-infected patients. Atherosclerosis 184: 72-77.

19. Crane HM, Grunfeld C, Willig JH, Mugavero MJ, Van Rompaey S, et al. (2011) Impact of NRTIs on lipid levels among a large HIV-infected cohort initiating antiretroviral therapy in clinical care. AIDS 25: 185-195.

20. Aberg JA, Gallant JE, Ghanem KG, Emmanuel P, Zingman BS, et al. (2014) Primary care guidelines for the management of persons infected with HIV: 2013 update by the HIV medicine association of the Infectious Diseases Society of America. Clin Infect Dis 58: e1-34.

21. National Cholesterol Education Program (NCEP) Expert Panel on Detection, Evaluation, and Treatment of High Blood Cholesterol in Adults (Adult Treatment Panel III): Third report of the National Cholesterol Education Program (NCEP) expert panel on detection, evaluation, and treatment of high blood cholesterol in adults (Adult Treatment Panel III) final report (2002) Circulation 106: 3143-3421.

22. Grundy SM, Cleeman JI, Merz CN, Brewer B, Clark LT, et al. (2004) Implications of recent clinical trials for the National Cholesterol Education Program Adult Treatment Panel III guidelines. Circulation 110: 227-239.

23. Stone NJ, Robinson J, Lichtenstein AH, Bairey CN, Blum CB, et al. (2013) ACC/ AHA Guideline on the Treatment of Blood Cholesterol to Reduce Atherosclerotic Cardiovascular Risk in Adults: A Report of the American College of Cardiology/ American Heart Association Task Force on Practice Guidelines. J Am Coll Cardiol 63: 2889-2934

24. Baigent C, Keech A, Kearney PM, Blackwell L, Buck G, et al. (2005) Efficacy and safety of cholesterol-lowering treatment: prospective meta-analysis of data from 90,056 participants in 14 randomised trials of statins. Lancet 366: 1267-1278.

25. Reinsch N, Neuhaus K, Esser S, Potthoff A, Hower M, et al. (2012) Are HIV patients undertreated? Cardiovascular risk factors in HIV: results of the HIVHEART study. Eur J Prev Cardiol 19: 267-274.

26. Lichtenstein KA, Armon C, Buchacz K, Chmiel JS, Buckner K, et al. (2013) Provider compliance with guidelines for management of cardiovascular risk in HIV-infected patients. Prev Chronic Dis 10: E10.

27. Nüesch R, Wang Q, Elzi L, Bernasconi E, Weber R, et al. (2013) Risk of cardiovascular events and blood pressure control in hypertensive HIV-infected patients: Swiss HIV Cohort Study (SHCS). J Acquir Immune Defic Syndr 62 396-404.

28. Smith CJ, Ryom L, Weber R, Morlat P, Pradier C, et al. (2014) Trends in underlying causes of death in people with HIV from 1999 to 2011 (D:A:D): a multicohort collaboration. Lancet 384: 241-248.

29. Klein DB, Leyden WA, Xu L, Chao CR, Horberg MA, et al. (2015) Declining relative risk for myocardial infarction among HIV-positive compared with HIVnegative individuals with access to care. Clin Infect Dis 60: 1278-1280.

30. American College of Cardiology and American Heart Association: ASCVD Risk Estimator.

31. Pencina MJ, Navar-Boggan AM, D'Agostino RB Sr, Williams K, Neely B, et al. (2014) Application of new cholesterol guidelines to a population-based sample. N Engl J Med 370: 1422-1431.

32. Zanni MV, Fitch KV, Feldpausch M, Lee H, Lu MT, et al. (2014) American College of Cardiology/American Heart Association and 2004 Adult Treatment Panel III cholesterol guidelines applied to HIV-infected patients with/without subclinical high-risk coronary plaque. AIDS 28: 2061-2070.

33. Monroe AK, Fu W, Zikusoka MN, Jacobson LP, Witt MD, et al. (2015) LowDensity Lipoprotein Cholesterol Levels and Statin Treatment by HIV Status Among Multicenter AIDS Cohort Study Men. AIDS Res Hum Retroviruses 31 593-602.

34. Sabin CA, d' Arminio M, Friis-Moller N, Weber R, El-Sadr WM, et al. (2008) Changes Over Time in Risk Factors for Cardiovascular Disease and Use of Lipid-Lowering Drugs in HIV-Infected Individuals and Impact on Myocardial Infarction. Clin Infect Dis 46:1101-1110. 